This item was submitted to Loughborough's Research Repository by the author.

Items in Figshare are protected by copyright, with all rights reserved, unless otherwise indicated.

\title{
Challenging popular representations of child trafficking in football
}

PLEASE CITE THE PUBLISHED VERSION

https://doi.org/10.1108/JCRPP-01-2018-0005

PUBLISHER

(c) Emerald Publishing

VERSION

AM (Accepted Manuscript)

PUBLISHER STATEMENT

This work is made available according to the conditions of the Creative Commons Attribution-NonCommercialNoDerivatives 4.0 International (CC BY-NC-ND 4.0) licence. Full details of this licence are available at: https://creativecommons.org/licenses/by-nc-nd/4.0/

\section{LICENCE}

CC BY-NC-ND 4.0

\section{REPOSITORY RECORD}

Esson, James, and Eleanor Drywood. 2019. "Challenging Popular Representations of Child Trafficking in Football”. figshare. https://hdl.handle.net/2134/28079. 
Challenging popular representations of child trafficking in football

\author{
James Esson \\ Department of Geography, Loughborough University, UK \\ j.esson@lboro.ac.uk \\ Eleanor Drywood \\ Law School, University of Liverpool, UK \\ e.w.drwyood@livepool.ac.uk
}




\section{Abstract}

Reports of human trafficking within the football industry have become a topic of academic, political, and media concern. The movement of and trade in aspirant young (male) footballers from West Africa to Europe, and more recently to Asia, dominates these accounts. This article provides an overview of scholarship on this topic, with a specific focus on exploring how this form of human trafficking intersects with broader debates over children's rights in the context of exploitation tied to irregular forms of migration. The article illustrates how popular narratives associated with the trafficking of young West African footballers mimic stereotypical portrayals of child trafficking, which have implications for the solutions put forward. It is argued that popular representations of football related child trafficking are problematic for several reasons, but two are emphasized here. First, they perpetuate a perception that the mobility of young African footballers entails a deviant form of agency in need of fixing, while simultaneously disassociating the desire to migrate from the broader social structures that need to be addressed. Second, and relatedly, they result in regulations and policy solutions that are inadvertently reductive and often at odds with the best interests of the children they seek to protect.

Key words: Africa; children; football; human trafficking; soccer 


\section{Introduction: "Never have I experienced such an immoral act."}

The last 5 years have seen several prominent professional football clubs, such as FC Barcelona, Atlético Madrid, and Real Madrid FC, sanctioned for breaking the Fédération Internationale de Football Association' (FIFA) regulations concerning the international recruitment of minors (players under the age of 18). In a particularly high-profile case, Manchester City FC were accused of trafficking a young player from South America. The Argentinian side Vélez Sarsfield made a formal complaint over Manchester City's recruitment of 15-year-old Benjamín Garré (Rumsby, 2016). In an interview on this issue Raul Gámez, Vélez's president, stated: "Never have I experienced such an immoral act" (Rumsby, 2016). In another notable and related news article in the international press, it was claimed that '15,000 young players are moved out of West Africa each year under false pretences' and that 'a lack of monitoring means the number of boys being trafficked abroad could be far higher, experts say' (Guilbert, 2015). Our reason for highlighting these accounts and passages is because they succinctly convey several assumptions and shortcomings in popular representations of child trafficking in the football industry. For example, what is it about Manchester City's actions that constituted child trafficking and what was it about their conduct that was so immoral? Meanwhile several questions also come to mind if we reflect on the claims above regarding the trafficking of young West African footballers in the piece by Guilbert (2015). For example: how were the figures obtained if there is a lack of monitoring? Why can the numbers not be far lower? Who are these experts?

This article therefore intervenes in debates over human trafficking within the football industry, and questions some of the often taken-for-granted narratives found within 
popular accounts on this issue. More specifically, the article aims to illustrate how elements of the narratives put forward mimic stereotypical portrayals of human trafficking, and demonstrate why this is problematic. The overarching argument is that popular representations of human trafficking within the football industry, particularly those involving children, implicitly promote a perception that the mobility of young footballers entails a problematic form of agency in need of fixing, and that the cause of exploitation and child rights abuses are due to mobility. The article demonstrates why this way of understanding human trafficking within football is problematic in two ways. First, we argue, it results in regulations and policy solutions that are inadvertently reductive and based on misunderstandings of the social context within which the players reside. Second, we draw upon the core principles of the United Nations Convention on the Rights of the Child 1989 (UNCRC), in particular the obligation to uphold the best interests of the child and the right of a child to have their voice heard in decisions affecting them, to argue that these solutions endorse a weak model of children's rights.

A note on the use of the term 'trafficking' in this article is apposite at this stage. The complex practices discussed below under the broad heading of 'football trafficking' are multi-faceted. In many instances, young players experience practices which fit within the legal definition of trafficking, found in Article 3 of the UN Protocol to Prevent, Suppress and Punish Trafficking in Persons. Yet, there are examples of highly problematic treatment involving the movement of players, leading to serious rights violations, which may fall outside this particular definition. This is discussed below, through an exploration of the distinction between trafficking in football and trafficking through football. In this paper, we use the term 'trafficking' in a broad sense, not 
necessarily always denoting practices that would fall within the strict legal definition. The focus of this paper is popular stereotypes around football 'trafficking' and how these lack a basis in the lived reality of young players, as such we are considering how these inaccuracies arise from grouping together a range of activities under the umbrella term of 'football trafficking'. To be restricted by a specific legal definition would be to overlook the exact phenomenon this paper seeks to capture: the often inaccurate way in which the term 'trafficking' is used in the context of football.

The first half of the article introduces the topic of 'football trafficking', and examines how popular representations of this issue are informed by stereotypical portrayals of child trafficking, which has deleterious implications for the solutions proposed to address the issue. The article then focuses on unpacking the residual bias in popular representations of football related human trafficking and the implications of this bias for understandings of, and responses to, this issue. Conclusions follow this.

\section{Human trafficking and modern slavery: football's dirty secret?}

The recruitment of football players at an early age, and the consequences for those who are unsuccessful in their quest for a contract with a professional club, has become the subject of scathing criticism from football administrators, sections of the liberal European media, and human rights activists (Darby et al. 2007; Donnelly and Petherick, 2004; van der Meij and Darby, 2014). While the focus of this paper is young West African players, it is important to begin by noting that cases of human trafficking in the football industry involve players from other regions also (see Meneses, 2013), with David (2004) documenting how teenage Brazilian footballers were being trafficked to 
Europe via a criminal syndicate operating between Brazil and Portugal, and how 24 Brazilian footballers (including several minors) were arrested and/or detained in the Dutch territory of Aruba (an island off the coast of Venezuela) allegedly on their way to the Netherlands for trials with football clubs. The extent of concern about the issue of human trafficking within the football industry, particularly cases involving minors from Africa, is perhaps best exemplified by the response from the United Nations High Commissioner for Refugees (UNHCR). In 1999 the UNHCR called for a thorough investigation into the practice of football agents 'purchasing' young African players in order to sell them to European clubs. The UNHCR report, published the same year, concluded by referring to the 'danger of effectively creating a modern day 'slave trade' in young African footballers' (cited in Armstrong and Giulianotti 2004, p.240). A European White Paper of 2009 drew similar conclusions.

The reports by the EU and UNHCR on human trafficking in football have emerged as part of a broader trend during the last fifteen to 20 years, which has seen a spate of documentaries, international conferences, journalistic pieces, and policy documents concerning the irregular migration and trafficking of young African football players to Europe (Guilbert 2015; Poli 2010a) and more recently to Asia (Akindes, 2013; Edwards, 2015). Various policy and media accounts have drawn attention to the exploitative practices that some young would-be players encounter, and the dire conditions some end up living in, because of unscrupulous individuals attempting to take advantage of young people's desire to reach the upper echelons of the sport. For example, in the mid 1990's Belgian Paul Carlier founded a pressure group called Sport and Freedom, and began campaigning on behalf of African players, often under eighteen years of age, who had been brought to Belgium by clubs and agents for trials and abandoned if 
unsuccessful (Darby et al. 2007; Donnelly \& Petherick, 2004). Sport and Freedom highlighted how many of the players who were unsuccessful in securing football contracts often remained as illegal immigrants on the streets of Belgium, and that in some cases they turned to prostitution as a means of survival (Donnelly and Petherick, 2004).

Another example from Belgium is the 442 cases of 'African soccer slaves' uncovered by the senator Jean Marie Dedecker when he exposed the illegal trade in Nigerian players within European football (Lindberg, 2006). His findings were especially noteworthy given that the situation in Belgium is argued to have improved following the passing of legislation in 1999 that restricted the ability of clubs to recruit foreign minors in sport. Dedecker also discovered that in addition to the 30 FIFA recognized football agents working within Belgium, there were approximately 170 'maverick agents' also trading players (Lindberg, 2006). According to the organization Culture Foot Solidaire (CFS), which was founded in 2001 by Jean-Claude Mbvoumin, a former Cameroonian international player, with aim of supporting young African players trafficked or unsuccessful in their trials with European football clubs, circa $€ 4000$ (Euros) is paid to these 'football agents' who claim to have obtained playing contracts for the player (Sparre, 2007). In some instances, players do indeed have contracts in place, albeit of an exploitative nature (see also Edwards, 2015: Poli, 2010b). Jean Marie Dedecker described how this took place in the Belgian context.

When they sell them to the clubs, they make double contracts. They make an official contract because the contract must be shown to the Belgian Football Federation. And there is a second contract made with the boys. The only thing 
they get in Belgium as minors is food and lodging (ibid cited in Lindberg 2006, p.3)

In most cases the alleged interest from a professional club is a charade, and the young people involved (sometimes as young as 11 years old) often remain in Europe in precarious circumstances without any means of subsistence (McDougall, 2008). Their disinclination to return home is often attributed to the shame they believe their situation will bring to their local community, particularly as family members often fund their trip (McDougall, 2008). The literature and accounts discussed here have played an indispensable role in bringing this issue of exploitation and abuse in the football industry to the attention of policy makers and the wider public. However, by focusing primarily on the mistreatment that young African migrants face in destination countries, the wider migratory process within which exploitation occurs is obscured, which has implications for how the process is conceptualised and represented. In order to clarify some of the misconceptions surrounding this particular form of migration, a step-by-step summary of the migration process is provided below (based on Esson, 2015a):

\subsection{An outline of football trafficking}

1. An intermediary claiming to be a football agent or talent scout identifies a player in a match or trial and offers him the opportunity to be signed by a foreign club. In some rare cases, the intermediary does not physically meet the player, as recruitment takes place via the Internet. 
2. The intermediary asks the player for money in exchange for securing this opportunity: this is akin to a 'finders fee'. Additional funds are also asked for to cover living costs and spending money in the destination country.

3. The player's immediate and extended family often sell family possessions, remove siblings from schooling or take out a loan to meet the costs. This is typically in the region of $€ 3-5,000$.

4. The player arrives in a destination country often on a short-term tourist visa. Contrary to popular media reportage the travel conditions are not always illegal and or dangerous. Players often arrive via legal channels, and in the instances where they do not, it is often using conventional modes of transportation with false travel documents.

5. On arrival in a destination country, the intermediary often takes the player's documents and any spending money for 'safe keeping'.

6. While in a destination country the player may or may not attend a trial with a club. In some cases, the agent abandons the player on arrival in a destination country.

7. If the player is not abandoned on arrival, they might be taken to multiple trials until a contract is offered and the agent is satisfied with the terms.

8. If the trials are successful the player signs a contract with the club. Problematically, the contract is typically exploitative with unfavourable terms for the player.

9. If the player is unsuccessful at his trials or his contract is not renewed and another club cannot be found, the intermediary abandons him. In most cases the intermediary will also take his 'finders fee', the player's documentation and any remaining money with him. 
10. Once the player realises the precarious nature of his situation he is often reluctant to return to his country of origin, and may decide to remain in the destination country illegally without any means of subsistence.

Steps 1-10 clearly constitute an irregular form of migration because it 'includes people who enter a country without the proper authority; people who remain in a country in contravention of their authority' (Koser, 2010; 183). But does any of the above constitute human trafficking as claimed by NGOs and the media? Aspects of the migratory process outlined above do appear to comply with understandings of human trafficking as outlined in the United Nations' (UN) Convention against Transnational Organized Crime and the associated Protocol to Prevent, Suppress and Punish Trafficking in Persons, Especially Women and Children. This is because Steps 1-5 feature an act, such as the recruitment and transportation of others, which is followed by the methods used to enforce those act(s), such as the use of fraud, coercion or other abuses of power or of a position of vulnerability. Meanwhile Steps 5-9 relate to a motive i.e. to obtain financial gains through exploiting the player. In some cases, after handing over money to some individual/individuals, the player does indeed obtain a contract or trial with a club, albeit of an exploitative nature. This is what is known as 'human trafficking in football' (Poli, 2010b). However, in most cases, the alleged interest from a foreign club is bogus, and the individual(s) abandon the player upon arrival in a destination country. This is known as 'human trafficking through football' (Poli, 2010b). Human trafficking in football and human trafficking through football are often conflated under the term 'football trafficking'. It is important to note that while cases of human trafficking in football comply with understandings of human trafficking as outlined in the 
UN Protocol on human trafficking there are some who question whether this applies to cases of human trafficking through football. This is because of uncertainty as to whether exploitation has actually occurred if the player is abandoned upon arrival. In other words, is this a case of fraud rather than human trafficking? Additionally, and perhaps controversially for some, the cases where players knowingly use false travel documents to enter a country could fall under the UN' Convention against Transnational Organized Crime Protocol on the Smuggling of Migrants by Land, Sea and Air. It should be borne in mind that where the player is a minor, the extent to which they can have entered into a contract with a smuggler is questionable, further muddying the waters in regard to the application of legal definitions of trafficking. FIFA, along with senior members from the Union of European Football Associations (UEFA), and the Confederation of African Football (CAF) have voiced their concerns about human trafficking within the football industry. However, this concern does not reflect fears about human trafficking as normatively defined in the outline above. Instead, the term human trafficking in these accounts is applied indiscriminately to international migration involving minors. It is worth noting that, whilst the focus here is on football trafficking, many of these definitional complexities are a feature of the application of legal regulation to trafficking in a broader sense.

The conflation of movement with exploitation is evident when one examines the Regulations on the Status and Transfer of Players (RSTP) first introduced in 2001 and modified most recently in 2015. Although the majority of clubs have now found loopholes and methods to evade them, the RSTP was designed to restrict clubs from purchasing and signing players under the age of 18 as part of efforts to 'protect the human rights of minors'. According to Article 19 of the RSTP, with the exception of the 
following three rules, international transfers are not permitted if a player is a minor (under 18); (1) a player's parents move to the country in which the new club is located for non-football related reasons; (2) the transfer takes place within the territory of the European Union or European Economic Area, the player is aged between 16 and 18, and the receiving club ensures the player is provided with a football education equivalent to the national standard alongside optimum living standards; (3) the player lives no further than $50 \mathrm{~km}$ from a national border and the club with which the player wishes to be registered in the neighbouring association is also within $50 \mathrm{~km}$ of that border. It is in relation to these regulations that clubs mentioned above in Section 1 were sanctioned, and Manchester City FC was accused in the international news media of trafficking 15-year-old Benjamín Garré from the Argentinian side Vélez Sarsfield.

It is in this context that media stories about football trafficking and policy and regulatory concerns about football trafficking among intergovernmental organisations and FIFA coalesce. The campaign materials, policy documents, newspaper reports and documentaries on the migration of young footballers all lend credence to claims about the problematic nature of football-related migration by listing the many abuses and problems migrants experience, such as homelessness, labour exploitation and sexual abuse. Indeed, the children's rights violations that may occur at various stages of the process outlined above are multifarious, impacting upon the child's right to survival and development, to healthcare, to education and to be protected from the dangers of economic exploitation and trafficking, amongst others. Whilst we do not, therefore, suggest that such abuses are insignificant or trivial, we do stress that the depiction of international migration as inherently precarious speaks to academic critiques of human trafficking discourses in the media and policy domain. Crucially, in relation to this paper, 
scholars have noted that unlike the migration of adults (those over 18) where controversies often hinge on questions of choice and agency (Salt 2000), if a minor is recruited and transported they have been trafficked no matter if they consented to the move or not (see Howard, 2012). Accordingly, the (non)agency of young migrants within popular narratives of football trafficking takes a particular form. To borrow O'Connell Davidson's (2011; 463) expression, the (child) migrant within these accounts have 'object like been removed, transported and put to use for purposes of exploitation'. Significantly, movement is foregrounded as the problem. Moreover, it positions origin countries as locations where a person is not harmed or socially disadvantaged (Anderson, 2007; Collins et al. 2013), and the wider context behind the act of migration is subsequently overlooked.

The allure of such reductive thinking lies in its mimicry of narratives found in broader human trafficking discourses, where emphasizing the connection between migration and exploitation serves to reinforce the severity of consequences linked to movement (Chuang, 2015), and to distinguish those involved as either 'victims' (young players) or 'villains' (football clubs/football agents). Furthermore, such thinking removes the agency of the child from the equation. Whilst it is tempting to focus on the vulnerability of young people who are exposed to trafficking-like practices and focus upon the need to protect them, casting children as passive victims who lack the capacity to make rational decisions about their lives inevitably leads to poor regulatory responses.

The UNCRC contains two axiomatic principles, to be used in interpreting and applying children's rights, which offer a useful framework for assessing regulatory responses to trafficking in football. The vulnerability of children and the need to offer special 
protection to young people is recognised in Article 3(1) which states that 'in all actions concerning children...the best interests of the child shall be a primary consideration'. This obligation is associated with a paternalistic approach to protecting the rights of the child: adults must assess what is best for children to ensure they are protected from harmful situations (Alston, 1994; Eekelaar, 2002; Parker, 1994). This obligation, however, must be balanced against the right of children 'to express their views freely' and to have these views 'given due weight in accordance with [their] age and maturity' (Article 12 UNCRC). This provision recognises the evolving capacities of the child and the importance of recognising the agency of young people. It is generally accepted, therefore, that approach to regulating young people's lives which properly recognises children's rights must be sensitive both to the need to protect children from harmful situations, on the one hand, and the importance of acknowledging their rational, decision-making capacities, on the other. This is an important balancing exercise to be borne in mind when assessing responses to the problems associated with football trafficking, particularly given the considerable literature highlighting the relatively sophisticated thinking behind young players' decisions to migrate (Darby, 2013; van der Meij et al. 2017).

In the section that follows, we discuss the implications of reductive thinking in relation to attempts to address football trafficking and the exploitation of minors in football, as well as the concomitant implications for 'protecting the human rights of minors'. 


\section{Problematic solutions}

It is within the discursive environment described above that key aspects of FIFA's Regulations on the Status and Transfer of Players (RSTP) function, as part of a broader strategy to limit the international movement of minors within the football industry. As mentioned above, a key function of the RSTP is to 'protect the human rights of minors' by restricting clubs from signing players under the age of 18 . In addition to the RSTP, a regulatory measure known as the 'Transfer Matching System' (TMS) was introduced in 2008. This is a web-based data information system designed to simplify and improve the transparency of transfer information, and keep a record of a player's biographical data. When two clubs undertake a transfer, they must enter identical information into the system and comply with the statutes outlined in FIFA's RSTP, otherwise the transfer will be blocked by FIFA and an 'International Transfer Certificate' (ITS) will not be given. Football Associations located in Sub-Saharan Africa have been particularly keen to use the TMS to address concerns over the irregular migration of African players as outlined above. Yet it is clear that if these measures are being put in place to limit mobility and thereby reduce risk and exposure to exploitation, they are not fit for purpose, given that there has been an increase in the numbers of international transfers involving minors, with a record 2,323 being registered in 2015 (Rowe, 2016). More worryingly, there have been notable inconsistencies in FIFA's policy response to the recruitment of minors, which fundamentally undermine their efforts to 'protect the human rights of minors'. For example, in March 2015, FIFA lowered the age at which the above mentioned international transfer certificate was required from 12 to 10 in order to extend regulatory protection to younger minors. However, that very month, FIFA ended its licensing scheme for player agents and devolved responsibilities for monitoring the conduct of 
player agents (now known as 'intermediaries') to national associations, thereby in effect deregulating this aspect of the football industry (Colucci 2016). It is unclear how deregulation and a further ambiguity around the rules governing the conduct of agents are in the best interests of minor players.

An alternative strategy to address the exploitation of minors in football, particularly in relation to human trafficking in football, is provided by the organization Culture Foot Solidaire (CFS). CFS proposes that altering the practices of clubs by way of an 'Ethical Transfer Charter' could reduce cases of irregular football migration. The Ethical Transfer Charter operates similarly to fair trade agreements for products such as bananas, chocolate and coffee. By signing the charter, clubs would be agreeing to only recruit minors who had been 'ethically sourced'. Such a solution resonates with a move in the children's rights world towards recognising organisations who commit to upholding children's rights and can demonstrate this through adhering to a set of principles, through membership of a scheme. The responses outlined above seek to target the demand for young West African players at the institutional level, and thereby limit the international migration of players and prevent human trafficking. On the one hand this is understandable, as it is easier to regulate institutions than to track down rogue intermediaries. This line of thought also connects to arguments that human trafficking can be eradicated by engaging in more ethical consumption of goods and services (Chuang 2015). But approaches targeting the 'demand' for trafficked persons have two potential recipients for their strategy: the consumers of goods and services produced or performed by trafficked people (in this case football fans, TV broadcasters and sponsors) and the employers or labour users of trafficked people (football clubs). 
The problem with a 'demand side' approach is the difficulty of targeting employer demand for trafficked labour per se, or consumer demand for goods or services produced or performed by trafficked people (see also Andrijasevic and Anderson, 2009). For example, as mentioned above, there have been high profile cases where clubs have been sanctioned for breaking the RSTP rules on signing players, but no evidence has been presented to suggest that the players were recruited for the purposes of exploitation. Rather the players appear to have been recruited at an early age as part of speculative commercial strategy. They are recruited at this early age not only because they are talented and would potentially strengthen the first team on the pitch, but also because it is more economical to sign them at this developmental stage before their value increases and they become subject to the advances of financially powerful clubs. We would argue therefore that the issue here is not that the clubs sanctioned for breaking the rules in the RSTP are involved in human trafficking according to its strict legal definition (although some are clearly involved in highly problematic practices), but that, like intermediaries working within an increasingly profitdriven industry, their conduct leaves them open to circumstances wherein they are likely to be involved in practices which contravene Article 32 of the United Nations Conventions on the Rights of the Child (UNCRC).

Article $32 \mathrm{UNCRC}$ recognises the right of the child to be protected from economic exploitation and from performing any work that is likely to be hazardous, to interfere with the child's education, or to be harmful to the child's health or physical, mental, spiritual, moral or social development. Curiously, however, there is very little engagement with the impact of the recruitment practices of high profile clubs on the rights of the child in much of the literature and debates mentioned above. Rather, comment has focused on 
a preoccupation with attention-seeking headlines regarding human trafficking and modern slavery. A lively debate in the children's rights arena currently revolves around whether an outright prohibition on child labour is justifiable, or whether it is preferable to recognise that certain forms of work can have a positive impact on a child's enjoyment of their rights and overall development by bolstering their 'desire to become independent... be helpful to their families, feel part of their social environments, and exercise their 'right to work' to fulfil their needs and construct their identity' (Ferreira 2014). Professional sport is a particularly fruitful context in which to consider this debate: the potential benefits of a successful football career provide a stark contrast to the insidious practices which fuel this industry, yet it remains a relatively under-explored area in the context of trafficking of footballers. Until the debate around the children's rights implications of a career in football becomes more developed, our thinking around solutions to the trafficking practices which provide the backdrop to success stories will remain stilted.

In conjunction with these demand side solutions, members from FIFA, CAF, and sections of the liberal European press, propose that African players will be less inclined to migrate (limiting supply) if the African football industry was developed (Darby et al. 2007). The problem with this approach is that it requires significant financial investment to achieve the required capacity building, investment that is not currently forthcoming. Thus, CFS argues that a more feasible solution is the dissemination of anti-trafficking messages via a media campaign (TV, radio and print). This would involve high profile West African players warning young people about the risks associated with football migration. CFS is also planning to create information centres in African countries to educate young people, families and clubs about the football industry and transfer 
regulations. At first glance, these responses appear quite diverse; for example, the first two address the issue of demand for young talent whereas the latter two address the supply of young talent. Yet, what connects them is an inherent bias, hiding in the implicit assumption that the exploitative practices encountered by young African footballers are inextricably linked to their movement. There is also an assumption that they are migrating for footballing reasons primarily. Therefore, if they stay put and play football in their country of origin they will be safe. This logic is in sync with the aforementioned notion of movement as the underlying cause of exploitation, thereby ignoring how players can also be exploited in the country of origin (see Armstrong, 2004; Brackenridge et al. 2006).

In the next section we want to examine and think through this sedentary bias and demonstrate why it is problematic by engaging with relevant academic literature and with research conducted in the Ghanaian capital, Accra. This fieldwork entailed multisited ethnography at three amateur neighbourhood football clubs with youth academies (under 12, 14 and 17). All three clubs had over 100 registered players and two senior teams. Over 116 training sessions across the three clubs as well as home and away matches were attended. Alongside participant observation, circa 200 interviews with players have been conducted in order to gain basic demographic information about participants and their thoughts on football and life in Ghana. These interviews were complemented by 20 interviews with coaches and club owners. 10 interviews were also conducted across two Premier League football clubs, the Ghanaian Football Association Regional office in Accra, the Ghana League Cubs Association, the Professional Footballers Association of Ghana and the Right to Dream Football Academy. Our aim here is to illustrate how protecting child rights within the football industry has to go 
beyond a focus on limiting the mobility of players to protect them from human trafficking, and how a sedentary bias implicit within such an approach might be at odds with said efforts to protect the rights of minors aspiring to pursue a career in professional football.

\section{Examining the sedentary bias: a Ghanaian case study}

In this case-study of trafficking in the Ghanaian context we map the children's rights impact of young people's experiences using central principles of the UNCRC. We argue that a turn towards neo-liberal policies in Africa has forced young people to take responsibility themselves for improving their life chances and, by extension, requires them to make choices which allow them to enjoy many of the rights that ought to be their basic entitlement as children. These are understandable choices, but ones which can expose young players to harmful and dangerous situations, from which they are then offered little protection by current regulation.

Economic reforms implemented by African countries following the adoption of neoliberal modes of governance have encouraged a range of private interests to take on the state's duties. In Ghana, these policies have weakened the belief that individuals belong to extended communities and Ghanaians have recently experienced the passing of the post-independence era of President Kwame Nkrumah's social developmentalism and state welfare provision. Consequently, the young people who took part in this research frequently commented on the difficulties of finding ways to survive in these economic circumstances, and explained how this construction of individuals as responsible for future life chances left them in a precarious position. It is a core principle of the UNCRC that children have a right to survival and development (Article 6), the realisation of 
which lies with states parties. Yet here we see a shift towards the delivery of social welfare policies by non-state actors and an increasing emphasis on the responsibility of rights holders to be proactive in finding ways to enjoy basic entitlements - effectively an outsourcing of the state's obligations in the children's rights field.

Alongside this framing of young Ghanaians as responsible for their future prospects is a widespread belief that migration offers a solution to economic uncertainty and marginalisation (see also van der Meij and Darby, 2014). This belief drew upon a prevailing idea that travelling to Europe or North America led to social mobility, and reproduced what Kalir (2005) terms a 'migratory disposition' to describe how people develop the desire to migrate through experiences of socioeconomic inequality and expressions of wealth connected to migration. Therefore, a decision to migrate can be motivated by the desire to live in a country with a higher level of realisation of children's rights, either through greater economic opportunity (and the consequent impact on the right to survival and development in Article 6 UNCRC) or, perhaps, through the ability to access better healthcare and education provision (Articles 24 and 28 respectively). Significantly, however, this migratory disposition is accompanied by a realisation that obtaining a visa to enter Europe or North America is becoming more difficult (Esson, 2015b).

The belief that migration will lead to improved life chances is not unique to aspirant footballers. It is a facet of broader cultural meanings of mobility circulating within Ghanaian society - something which has also been highlighted in non-football related research with young people in other West African contexts (Martin et al. 2016). Therefore, while players are keen to migrate in order to play at a higher level (Darby 
2013), it is important not to attribute this desire to migrate solely to a 'culture of mediocrity' within the local football industry. This is important because structural relations within the football industry interact with those beyond in ways that are currently insufficiently acknowledged in the solutions proposed to address irregular football migration. The young players interviewed typically explained how the West African footballer that was able to harness his sporting ability, and migrate to a well-paid European League where he would get a maximum return on this ability, was the embodiment of self-reliance and entrepreneurialism (Esson, 2016). Accordingly, a number of young people now view a football career as a way to sidestep an education system argued to lead to either unemployment or employment in the informal economy, and as a vehicle for development through the deployment of individual autonomy (see also Ungruhe, 2017). The latter point is not unique to young Ghanaians and is also evident in other sub-Saharan African countries and in parts of South America (de Vasconcellos Ribeiro and Dimeo, 2009; Poli and Besson, 2015).

As noted by van der Meij and Darby (2014), the decision to pursue a football career is often made as part of a household livelihood strategy, with football increasingly seen by Ghanaian families as a way to improve their socio-economic prospects. Here, then, we observe an interesting trend in the relationship between young players' decision to migrate and the core principles of the UNCRC. As is their right under the Convention, these young players are demonstrating their capacity to make choices about their lives. Indeed, these are choices motivated by a desire to live a life which they believe will allow them to access a higher level of rights across a range of areas of their lives. In other words, they are taking responsibility for seeking out and realising these rights. Yet, as we will see, this level of autonomy is not balanced by a complementary need to ensure 
actions are taken in the child's best interests such that they are protected from harm. In order to turn footballing ambitions into reality, entering the Ghanaian football industry and joining a football club becomes the obvious course of action (see also van der Meij et al. 2017).

CAF and FIFA fear the academy system provides clubs and organized speculators with a mechanism to circumvent transfer regulations, such as the ban on the international transfer of minors (under 18s), and continue their procurement for a nominal financial outlay. But the picture is far more complex on the ground. For example, in Ghana, the last two decades has seen an increase in the establishment of amateur youth football clubs and academies for under-17s, and an even more notable increase in player registrations in the youth leagues. This increase in the establishment of football academies is being driven by unemployed and/or precariously employed young people in their twenties and early thirties who have embraced the neoliberal mind set and see themselves as entrepreneurs. They view owning a youth team as a business not a recreational activity or hobby. Somewhat ironically, this situation is linked to international transfer regulations introduced by FIFA in 2001. FIFA attempted to discourage international migration of minors by deterring rich—i.e. European—clubs from signing talented young players based in Africa and South America. A ruling was made stipulating that clubs involved in the training and education of players between the ages of 12 and 23 must receive financial compensation from the buying club. This compensation can range from hundreds to millions of US dollars. Crucially, this financial value can only be realised when a player is transferred to another club. This has resulted in intense financial speculation and increased trading of young Ghanaian 
players by academy owners, who are searching for the next star to try to sell at a profit to a wealthier foreign club.

We began this section by acknowledging that underpinning a young player's decision to migrate are considerations which go straight to the heart of the rights they enjoy under the UNCRC: the belief in a better standard of life, greater economic opportunity, enhanced healthcare and education provision. Whilst the framework of the UNCRC recognises the autonomous decision-making capacities of children, indeed it is the very essence of this principle that - under the right circumstances - a young person can make rational, well-informed choices to pursue a particular life course, the Convention also emphasises the need to offer protection from harmful situations. This includes, for example, measures which combat trafficking in children (Article 35) and an obligation to protect young people from economic exploitation (Article 34). At the very worst end of the spectrum, we see egregious rights violations in relation to those players who are trafficked and who, as a result, suffer a range of rights violations such as abuse, neglect and maltreatment, which Article 19 UNCRC states they should be protected from. But we also see a football transfer system that is structurally skewed towards prioritising economic gain over the welfare of the child. We touched briefly earlier on the debate around a child's right to be protected from economic exploitation and the resulting debates around child labour. When we set these questions within the context of an industry that is so clearly geared towards profit, these questions take on a more sinister tone. It is particularly concerning to see that some of the regulatory responses specifically targeting young players completely fail to meet basic welfare needs and, in some cases, exacerbate the situation. 
Football academies are therefore increasingly geared towards the grooming and export of players to foreign clubs, and we can see how FIFA's attempts to limit the international migration of players is being undermined by one of its own policy measures. Moreover, we have a convergence in the Ghanaian football industry of economic liberalisation with migration-based efforts at upward social mobility. Thus, this brief case study illustrates why the sedentary bias in solutions to addressing the issue of exploitation of minors within football is problematic. Because in the case of young Ghanaian males they are not just trying to migrate because they are footballers, rather the attraction of a career in football is the outcome of broader structural changes taking place within Ghanaian society, which in the absence of state welfare provision encourages young people to be job creators not job seekers. Meanwhile, the financial logic of the football industry appears to provide opportunities to migrate in a context where social mobility is associated with international mobility, but the opportunities to be internationally mobile are rescinding. This point illustrates a problem with the proposed awareness campaigns and information centres discussed above, as these approaches suggest that a solution to human trafficking in and through football is providing players with more information, which will in turn allow them to make better choices. Here, better choices implicitly mean opting not to migrate. There is an irony to this approach because it uses neoliberal logic to foreground individual conduct and responsibility, but it does so in a way that diverts attention away from the very structural conditions caused by neoliberal inspired policies that young people were shown to be trying to escape. The fact that there are fewer options for people in less developed parts of the world to migrate legally is also overlooked. 


\section{Conclusions}

This article has identified popular representations of child trafficking and football, challenged the basis of these representations and illustrated how they feed ill-informed regulatory responses. We began by outlining the narratives which inform understandings of trafficking in football and trafficking through football, pointing in particular to the way in which they problematize young player's agency and suggest that stemming mobility offers a solution. We used the axiomatic principles of welfare and agency, as found in the UNCRC, as a framework for unpacking the tension within responses to trafficking between the need to protect children and to empower their decision-making capacities. We demonstrated how the ill-informed assumptions about football trafficking undermine regulation in the area and inevitably lead to ineffective responses. We then turned to a case-study of Ghana and considered the sedentary bias at the heart of proposed solutions, which tend to be geared towards persuading a player not to migrate, thus ignoring the wider structural inequalities which lie at the heart of the decision to pursue better life opportunities through football in the first place. We argued that the UNCRC encourages autonomy and agency in young people, but places a clear obligation to ensure that this is balanced against the need to protect children from harmful situations. The latter obligation is clearly not being fulfilled through current responses.

Our key message, therefore, is the need to improve the research base underpinning regulatory responses to football trafficking. But this is a plea that requires further nuancing in terms of the framework for this work. First, we would point to the need for better understanding of the local context in which football trafficking takes place. We 
have clearly demonstrated, through our case-study, that decisions around football trafficking can only be understood in the wider context of Ghanaian politics and social policies of recent years. To try to dissociate regulatory responses from this context would only undermine their eventual efficacy. We have pointed to evidence of trafficking around football in other regions of the world, each of which will present their own local, contextual challenges. Of course, this suggestion requires us to acknowledge the inherent difficulty in regulating any area at a global level: it is a key message of this paper that both football and children's rights require sensitive unpacking in their local, cultural context. Whilst specific policy recommendations are beyond the scope of this paper, we suggest that attempts to improve regulation in this area must be sufficiently adaptable so as to work in a range of specific contexts. Second, we would argue for greater engagement between children's rights frameworks and obligations and the challenges presented by football trafficking. We have seen how current responses often produce outcomes which are injurious to basic children's rights standards and that there is little regard for these principles in the operation of the football transfer system. As such, we call for work on trafficking in football which is informed by the UNCRC. Finally, we highlight the need for all actors in and around football trafficking to collaborate on solutions. We have pointed often to the failure of states to fulfil their obligations in the children's rights arena through social policies, whilst also highlighting the shortcomings of global sports regulators such as FIFA and CAF. Governing bodies operate in a quasi-legal capacity when regulating sports and, as such, must be as involved as states and international organisations in working towards solutions. So, whilst our message is simple - that better evidence around football trafficking must 
underpin responses - we would also demand that this evidence gathering is done in a context driven, children's rights informed way. 


\section{References:}

Akindes, G. A., (2013) South Asia and South-East Asia: new paths of African footballer migration. Soccer \& Society, 14(5), 684-701.

Alston, P., (1994) The Best Interests Principle: Towards a Reconciliation of Culture and Human Rights. International Journal of Law and the Family, 8, 1-25.

Anderson, B., (2007). Motherhood, apple pie and slavery: Reflections on trafficking debates. Centre on Migration, Policy and Society, University of Oxford.

Andrijasevic, R. and Anderson, B., (2009). Anti-trafficking campaigns: decent? honest? truthful? Feminist Review, 92(1), pp.151-155.

Armstrong, G., (2004). The lords of misrule: football and the rights of the child in Liberia, West Africa. Sport in society, 7(3), 473-502.

Armstrong, G., \& Giulianotti, R., (2004). Football in Africa: conflict, conciliation and community. Palgrave Macmillan.

Brackenridge, C., Pitchford, A., Russell, K., \& Nutt, G. (2006) Child welfare in football: An exploration of children's welfare in the modern game. Routledge.

Collins, R., Esson, J., O'Neill Gutierrez, C. and Adekunle, A., (2013). Youth in motion: spatialising youth movement (s) in the social sciences. Children's Geographies, 11(3), pp.369-376.

Colucci, M., (2016). The FIFA Regulations on Working with Intermediaries: Implementation at national level., International Sports Law and Policy Bulletin, 1/2016 
Chuang, J., (2015). The Challenges and Perils of Reframing Trafficking as' Modern-Day Slavery'. Anti-Trafficking Review, (5), p.146.

Darby, P., (2013). Moving players, traversing perspectives: Global value chains, production networks and Ghanaian football labour migration. Geoforum, 50, pp.43-53.

Darby, P., Akindes, G., \& Kirwin, M. (2007) Football academies and the migration of African football labor to Europe. Journal of Sport and Social Issues, 31(2), 143-161. David, P., (2004). Human rights in youth sport: a critical review of children's rights in competitive sport. Routledge.

De Vasconcellos Ribeiro, C. H., \& Dimeo, P., (2009). The experience of migration for Brazilian football players. Sport in Society, 12(6), 725-736.

Donnelly, P., \& Petherick, L. (2004) Workers' playtime? Child labour at the extremes of the sporting spectrum. Sport in society, 7(3), 301-321.

Drywood, E. W., (2016). "When we buy a young boy...": Migrant Footballers, Children's Rights and the Case for EU Intervention', in I. Iusmen, \& H. Stalford (Eds.) The EU as a Children's Rights Actor. Barbara Budrich. 191-219

Edwards, P., (2015). “Underage African Footballers 'Trafficked’ to Laos,” BBC News, June 21, 2015, http://www.bbc.co.uk/news/world-africa-33595804.

Eekelaar, J. (2002) Beyond the Welfare Principle. Child and Family Law Quarterly, $14(3), 237-250$

Esson, J., (2015a). Better off at home? Rethinking responses to trafficked West African footballers in Europe. Journal of Ethnic and Migration Studies, 41(3), 512-530. 
Esson, J., (2015b). You have to try your luck: male Ghanaian youth and the uncertainty of football migration. Environment and Planning A, 47(6), 1383-1397.

Esson, J., (2016). Football as a Vehicle for Development: Lessons from Male Ghanaian Youth in Ansell, N., Klocker, N., Skelton, T., (Eds) Geographies of Global Issues: Change and Threat, Springer Singapore. pp.1-18.

Ferreira, N., (2014). Child Labour and EU Law and Policy: A Regional Solution for a Global Issue in lusmen, I., Stalford, H., (Eds) The EU as a Children's Rights Actor, Barbara Budrich Opladen. pp. 259-288

Guilbert, K., (2015). “Chasing Dreams: Young African Footballers Duped, Dumped by Traffickers," Reuters Africa, December 7, 2015, http://af.reuters.com/article/sportsNews/idAFKBNOTQ0IS20151207.

Hawkins, E., (2015). The lost boys: Inside football's slave trade. Bloomsbury.

Howard, N., (2012). Accountable to Whom? Accountable for What? Understanding antichild trafficking discourse and policy in southern Benin. Anti-Trafficking Review DOI: http://dx.doi.org/10.14197/atr.201213

Kalir, B., (2005). The Development of a Migratory Disposition: Explaining a 'New Emigration, International Migration 43(4), 167-196.

Koser, K., (2010). Dimensions and dynamics of irregular migration. Population, Space and Place, 16(3), pp.181-193.

Lindberg, K., (2006). "The man who traced 442 soccer slaves". Play the game. Available at: http://playthegame.org/upload/Magazine\%202005/themanwhotraced442slaves.pdf 
Martin, J., Ungruhe, C. and Häberlein, T., (2016). Young Future Africa-Images, Imagination and its Making: An Introduction. AnthropoChildren. No.6, 1-18.

McDougall, D (2008). "The Scandal of Africa's Trafficked Players" The Observer. http://www.guardian.co.uk/football/2008/jan/06/newsstory.sport4

Meneses, J. P, (2013). Niños futbolistas. Blackie Books.

O'Connell Davidson, J., 2011. Moving children? Child trafficking, child migration, and child rights. Critical social policy, 31(3), pp.454-477.

Parker, S., (1994). The Best Interests of the Child: Principles and Problems. International Journal of Law and the Family, 8, 26-41

Poli, R and Besson, R., (2015). 'Football and Migration: A contemporary geographical analysis', in R. Elliot and J. Harris (Eds.) Football and Migration: Perspectives, places, players. Routledge

Poli, R., (2010a). African migrants in Asian and European football: hopes and realities. Sport in Society, 13(6), pp.1001-1011.

Poli, R., (2010a). The migrations of African football players to Europe: Human Trafficking and Neo-colonialism in question. Paper presented at Football for Development. Vienna, Austria. Available at:

http://www.footballfordevelopment.net/uploads/tx_drblob/storage/Poli_migration-ofAfrican-football-players_01.pdf

Poli, R., (2010b). 'Agents and intermediaries' in Chadwick S (Ed) Managing Football: An International Perspective. Oxford: Butterworth Heinemann, 201-216. 
Poli, R., (2010c). African migrants in Asian and European football: hopes and realities. Sport in Society, 13(6), pp.1001-1011.

Rowe, M., (2016). The Beautiful Game? Geographical, 88 (11), November: 33-39.

Salt, J., (2000). Trafficking and human smuggling: A European perspective. International Migration, 38(3), pp.31-56.

Sloth-Nielsen, J., (2016). Children's Rights in Africa: A Legal Perspective. Routledge. Ungruhe, C. and Esson, J., (2017). A Social Negotiation of Hope: Male West African Youth," Waithood" and the Pursuit of Social Becoming through Football. Boyhood Studies, 10(1), pp.22-43.

Ungruhe, C., (2017). Mobilities at Play: The Local Embedding of Transnational Connections in West African Football Migration. The International Journal of the History of Sport, pp.1-19.

Van der Meij, N., Darby, P. and Liston, K., (2017). The downfall of a man is not the end of his life": Navigating involuntary immobility in Ghanaian football'. Sociology of Sport Journal. 34(2) 183-194.

Van der Meij, N. and Darby, P., (2014). "No one would burden the sea and then never get any benefit". in Elliott, R. and Harris, J. (eds) Football and Migration. Perspectives, Places, Players. Routledge. 